\title{
How Foraging Behaviour and Resource Partitioning Can Drive the Evolution of Flowers and the Structure of Pollination Networks
}

\author{
Miguel A. Rodríguez-Gironés ${ }^{*}{ }^{, 1}$ and Luis Santamaría ${ }^{*, 2}$ \\ ${ }^{l}$ Estación Experimental de Zonas Áridas, CSIC, Ctra. de Sacramento S/N, La Cañada de San Urbano, 04120 Almería, \\ Spain \\ ${ }^{2}$ Instituto Mediterráneo de Estudios Avanzados (IMEDEA, CSIC-UIB), C/ Miguel Marquès 21, 07190 Esporles, Islas \\ Baleares, Spain
}

\begin{abstract}
Many flowers are visited by a large array of pollinators, often belonging to different taxonomic groups, and many pollinator species visit a wide array of flowers with different morphologies. This observation has led pollination ecologists to question the role played by pollinators in flower diversification and the extent to which floral similarities reflect convergent evolution to specific pollinator assemblages rather than other factors, such as phylogenetic constraints. In this paper, we review several ecological and evolutionary models that help to explain how pollinators can play a key role in floral evolution despite heterogeneities in plant-pollinator interactions. Our basic tenant is that, in animal pollinated species, the trajectory of pollen grains is determined by the foraging strategy of pollinators. Starting from a first approximation based on optimal foraging theory, ecological models related to the principles behind the ideal free distribution can be used to predict differences in floral and pollinator traits that will lead to resource partitioning. Building upon these results, evolutionary models based on game theory can be used to predict changes in traits of flowers and pollinators. These models show that pollinators can drive the evolution of floral divergence in the presence of behavioural noise and temporal variability in the composition of pollinator ensembles.
\end{abstract}

Keywords: Pollination syndromes, co-evolution, optimal foraging theory, nectar barriers, flower diversification, spatiotemporal heterogeneity.

\section{INTRODUCTION}

Interest in the fertilisation of crops provided mankind with detailed knowledge of flower-insect interactions from early history. For example, hand pollination of palm trees was introduced in Mesopotamia some 3000 years ago (Meeuse 1981), and the role of wasps in fig pollination was (partially) understood by Herodotus (485-425 B.C.) and Aristotle (ca. 350 B.C.) (Kevan \& Phillips, 2001). Nevertheless, Smyrna figs introduced into California in the late $18^{\text {th }}$ century failed to bear fruit because the suggestion that wasps were required for their fertilisation was disregarded (Reasoner 1891; Condit and Swingle 1947).

As the first introduction of Smyrna fig trees into California was proving unsuccessful, botanists were performing the first systematic studies of the role that insects played in plant reproduction (Kölreuter 1761; Sprengel 1793). The description of the subtle mechanisms through which flowers manipulate visitors into removing pollen from their anthers and depositing it on their stigmas (Sprengel 1793) did not gain immediate acceptance, but it would be

\footnotetext{
*Address correspondence to these authors at the Estación Experimental de Zonas Áridas, CSIC, Ctra. de Sacramento S/N, La Cañada de San Urbano, 04120 Almería, Spain; Tel: (+34) 950 281045; Fax: (+34) 950 277100; Email: rgirones@eeza.csic.es; Instituto Mediterráneo de Estudios Avanzados (IMEDEA, CSIC-UIB), C/ Miguel Marquès 21, 07190 Esporles, Islas Baleares, Spain; Tel: (+34) 971611823; Fax: (+34) 97161 1761; E-mail: 1santamaria@imedea.uib-csic.es

Special Issue Editors: Jordi Moya Larano and José M. Montoya
}

pushed to the centre of the scientific stage when Darwin $(1859,1862)$ presented the fit between flowers and pollinators as evidence supporting his evolutionary theory.

The need to support the theory of evolution through natural selection at a time when it was struggling for general acceptance led many biologists to follow Darwin's footsteps and concentrate their studies of pollination ecology on systems where the co-adaptations between flowers and insects were most obvious. This choice was probably reinforced by the non-trivial advantage of working with simple, well defined systems comprising just two species ("the" flower and "the" pollinator) linked by strong interactions (therefore easier to detect and measure). The prevalence of pollination examples in evolutionary textbooks attests to the success of this research strategy.

With most pollination ecologists seeking examples of tight co-adaptation between flowers and their pollinators to support the theory of evolution through natural selection, the view that floral traits reflected evolution and adaptation to the flower's pollinators (Baker 1963; Grant and Grant 1965; Fægri and van der Pijl 1966; Stebbins 1970) could not take long to develop. But this idea came hand-in-hand with the observation that most flowers can be classified according to the "adaptational groups" (Delpino 1873-1874) or "pollination syndromes" (Fægri and van der Pijl 1966) to which they belong, an observation that reduced the potential biases in the selection of study systems and aimed at simplifying a reality whose complexity (owing to the diversity of pollinators visiting some flowers, and vice-versa) began to be 
perceived. Although pollination syndromes have been variously defined, essentially they are "suites of floral traits proposed to reflect adaptations to one or another pollinator type roughly at the level of orders (e.g., beetles vs. butterflies $v s$. bees) or above (e.g., beetles vs. birds)" (Waser et al. 1996). Note therefore that they tend to group suites of flower and pollinator species into large functional, rather than taxonomic, units. The existence of pollination syndromes supposedly reflects a process of convergent evolution (Fægri and van der Pijl 1979): plants that share pollinators or that have pollinators with similar morphology and behaviour, are subject to similar selective pressures and end up having similar phenotypic traits.

The idea that diverse floral phenotypes reflect specialisation onto different groups of pollinators was challenged in 1996 by two publications (Herrera 1996; Waser et al. 1996) that pointed out that (i) the flowers of most plant species are visited, and presumably pollinated, by several different pollinator species, often belonging to different taxonomic groups; (ii) most pollinators visit the flowers of several to many plant species, often belonging to different pollination syndromes; and (iii) the pollinators visiting the flowers of a plant species in one population may well be absent in another population or the following season. If plant-pollinator interactions are characterised by their generalisation and spatiotemporal heterogeneity, it is difficult to see how the evolutionary trajectory of the floral traits of any plant species can be driven by a single pollinator.

The debate surrounding the usefulness and even existence of pollination syndromes continues today. There is little question that convergent evolution has played a role in floral evolution (Goldblatt 1986; Bernhardt 2000; Glover et al. 2004; Pérez et al. 2004; Waterman et al. 2009), so the debate centres on the prevalence of this phenomenon. For instance, analysing Robertson's (1928) observations of 15,172 visits to 441 flowering plant species around Carlinville, Illinois, Waser et al. (1996) concluded that $91 \%$ of the native species were generalists, because they were visited by more than one pollinator species, while Fenster et al. (2004) concluded that some $75 \%$ of the same species were specialists, because they were visited by a single functional group of pollinators. In a recent attempt to detect the existence of pollination syndromes, Ollerton et al. (2009) scored the flowers of 482 species in six communities for traits included in the definition of pollination syndromes. They used a complex statistical analysis to compare the floral phenotype of each species studied with the phenotypes expected for the most common pollination syndromes, and concluded that the vast majority of the flowers in their communities did not cluster in phenotype space around the coordinates where the pollination syndromes would be expected. Nevertheless, it seems likely that the points corresponding to the different species are not uniformly distributed in phenotype space, and it is even possible that a different statistical analysis had led to different conclusions. Indeed, Momose et al. (1998) concluded that pollination syndromes provided a useful framework to classify most of the 270 species of flowering plants that they studied in a tropical community: flowering time, reward and floral trait, but not colour, were associated with the main pollinator of most flowers. Likewise, a study of 114 flowering plant species in Tasmania concluded that visitor profiles were sometimes consistent with classic pollination syndromes, even though these syndromes were unreliable predictors of floral visitors (Hingston and McQuillan 2000). Indeed, the majority of flowering plants were unspecialised in their morphology and hosted a diverse array of visitors.

Despite the controversy surrounding the existence of pollination syndromes, and the extent to which "most" flowering plants have generalist or specialist pollination syndromes (Waser et al. 1996; Johnson and Steiner 2000; Fenster et al. 2004; Ollerton et al. 2009), two points seem undisputed: although (1) many floral traits reflect adaptive responses to selection by pollinators (Ollerton et al. 2009), (2) the pollinators of a particular flower cannot necessarily be predicted from the description of the flower (Waser et al. 1996; Momose et al. 1998; Hingston and McQuillan 2000; Fenster et al. 2004; Ollerton et al. 2009). As Johnson and Steiner (2000) point out, "pollination syndromes were intended to be used as a formal description of patterns of convergent evolution among unrelated plants, not as a substitute for field observations."

Although several authors have argued that we cannot understand flower evolution without considering the foraging strategies of pollinators (Waser and Price 1998), plantpollinator studies have traditionally disregarded them (Herrera 2002). In this paper we argue that an explicit consideration of such strategies can go a long way to reconcile the different postures regarding the existence, and implications, of pollination syndromes. In particular, it may help explain how, and under which circumstances, functionally-different pollinators may be observed to have either overlapping or mutually-exclusive ecological niches (defined in terms of flower choices).

\section{SPECIALISATION AND DIVERGENCE OF FLORAL TRAITS}

Several recent reviews discuss the tension between specialisation and generalisation in plant pollination systems and the effects of specialisation on floral divergence (Waser et al. 1996; Wilson and Thomson 1996; Johnson and Steiner 2000; Fenster et al. 2004). In this section, therefore, we will only summarise the key results needed to understand our argument. Most research in evolutionary pollination ecology is based on the idea that floral traits are selected to attract efficient pollinators, to maximise the efficiency of pollen transfer from anthers to pollinator to stigma, and to deter undesired visitors who would otherwise consume costly resources intended to attract pollinators. These three principles are the main pillars on which evolutionary pollination ecology has been built - despite a growing recognition of the selection pressures that abiotic factors, herbivory and seed predators exert on floral morphology (Herrera 1996; Strauss and Whittall 2006).

In an attempt to solve the paradox that most flowers are morphologically specialised despite the fact that they are visited by several pollinator species, Stebbins (1970) formulated the "most effective pollinator principle", according to which floral traits are shaped by those pollinators that visit the flower most frequently and effectively. Effectiveness is taken to be an index of the number of pollen grains that each pollinator transfers from the anthers of a flower to the stigma 
of a conspecific flower. Effectiveness should therefore be proportional to the product of three probabilities: probability that pollen is transferred from anthers to pollinator, probability that the pollinator visits another flower of the same species before the pollen is lost, and probability that the pollen is transferred from the pollinator to the stigma of the new flower. While the requirement that the pollinator travels from one flower to another of the same species in order to achieve cross fertilisation is anything but new (see e.g. Heinrich and Raven 1972; Feinsinger 1983), most authors have treated pollination effectiveness as a trait pertaining to each plant-pollinator pair of species, independent of the ecological context where it is measured (but see e.g. Waser 1983 for an earlier description of the logic we advocate). Inasmuch as the foraging choices of pollinators are context dependent, such treatment makes the implicit assumption that pollination effectiveness is determined by the mechanical fit between flower and pollinator, and independent of the movement patterns of the pollinator. As we explain below, models of flower specialisation (Waser $e t$ al. 1996; model where different pollinator species have additive effects on plant fitness, referred to as "model without interactions" in Aigner 2001) that fail to take into account the foraging choices of pollinators make completely different predictions from models that take the foraging choices of pollinators, and the probability of conspecific pollen transfer, explicitly into account ("model with interactions" in Aigner 2001; Rodríguez-Gironés and Santamaría 2005, 2007; Sargent and Otto 2006; Rodríguez-Gironés and Llandres 2008; see also Strickler and Vinson 2000 for a model of selfed versus crossed pollen transfer).

\section{EVOLUTION OF NECTAR CONCEALMENT}

Prominent field biologists have interpreted many floral traits as barriers that prevent undesired visitors from consuming the reward intended for more effective pollinators (Müller 1873; Janzen 1971; Heinrich and Raven 1972). While ignoring the foraging behaviour of pollinators leads to the conclusion that features that exclude less-effective pollinators are unlikely to evolve, particularly if these features interfere with the exploitation of flowers by "more effective" pollinators ("model without interactions" in Aigner 2001; Fenster et al. 2004), explicit consideration of the foraging strategies of pollinators leads to a very different answer.

Possingham (1992) considers the optimal foraging strategy of two pollinator species that compete for the resources provided by two flowering plant species. He assumes that the two plant species are spatially segregated and pollinators must choose the patch where they forage, and that the two pollinator species differ in the relative efficiency with which they exploit the two flower types. With these assumptions (the first of which is implicit), Possingham (1992) shows that at least one species should behave as a specialist, while the other species will behave as a specialist or a generalist depending on the specific parameter values of the model. In other words: as long as there are differences in the time that pollinators must invest in exploiting flowers, there should be partial resource partitioning. In order to derive analytical results, Possingham (1992) was forced to make a number of simplifying assumptions. But his results are quite robust: resource partitioning generalises to communities with any number of plant and pollinator species and to more realistic fitness functions (Rodríguez-Gironés 2006).

Rodríguez-Gironés and Santamaría (2005) used Possingham's (1992) results to model the evolution of nectar concealment in a community with two plant and two nectarivore species. Possingham's (1992) model is closely related to the ideal free distribution (Fretwell and Lucas 1970): it assumes that individuals choose the foraging option that maximises their intake rate, and that individual decisions lead to community patterns. Resource partitioning (Possingham 1992; Rodríguez-Gironés 2006 and other models that will be discussed later) therefore operates at the ecological time scale, as individual foragers compare available options and decide to forage on the most profitable ones. But these ecological processes have important evolutionary consequences. Suppose that nectarivore A is a more effective pollinator of plant 1 than nectarivore B. Suppose further that flowers of plant 1 have a trait, that we call nectar barrier, that interferes with nectar exploitation. If there is genetic variability for the strength of the nectar barrier and the detrimental effect of the nectar barrier is stronger for the less effective pollinator (nectarivore B) than for the more effective pollinator (nectarivore A), then the strength of the nectar barrier will increase in the population (Fig. 1). At the evolutionarily stable strategy, the strength of the nectar barrier is the minimum value for which inefficient pollinators are totally excluded from foraging at flowers of plant 1 (Rodríguez-Gironés and Santamaría 2005).

To obtain analytical results, Rodríguez-Gironés and Santamaría (2005) were forced to make the same simplifications as Possingham (1992). In particular, they assumed that plants were spatially segregated and that pollinators chose whether to forage at a single patch or at both patches. To test the generality of the results, Rodríguez-Gironés and Santamaría (2007) considered the possibility that deep corolla tubes evolve as nectar barriers (Belt 1874; Janzen 1971; Heinrich and Raven 1972; Laverty 1980; Castellanos et al. 2004). According to optimal foraging theory, variability in corolla depth and proboscis length should lead to resource partitioning: nectar feeders with long proboscides should specialise in flowers with deep corolla tubes, and nectar feeders with short proboscides in shallow flowers (Peleg and Shmida 1992; Rodríguez-Gironés and Santamaría 2006). When flowers with long and short corolla tubes are spatially segregated, at least one nectarivore species should forage exclusively on one flower type (Rodríguez-Gironés and Santamaría 2006). When flowers grow intermingled, with a random spatial distribution, however, things are more complicated. In the absence of competition for resources, pollinators should land on every flower they encounter, and extract whatever nectar they can reach. As competition for resources increases, however, pollinators should become more and more selective: resource partition hence increases with resource competition (Peleg and Shmida 1992; Rodríguez-Gironés and Santamaría 2006). As RodríguezGironés and Santamaría (2007) show, the level of resource partitioning expected in communities where flowers grow intermingled is sufficient to trigger the evolution of long corolla tubes. 


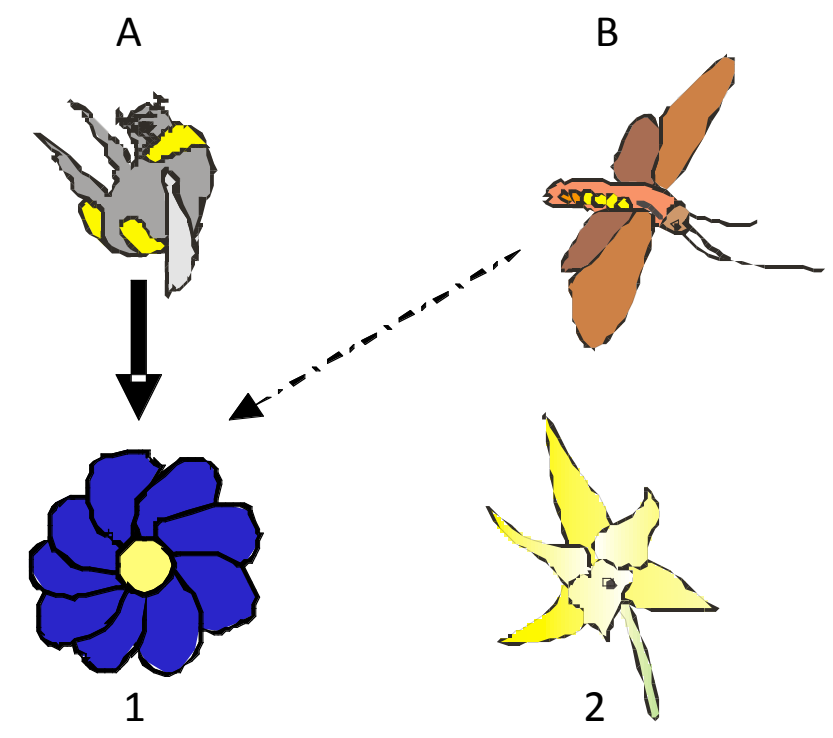

\section{Exploitation time}
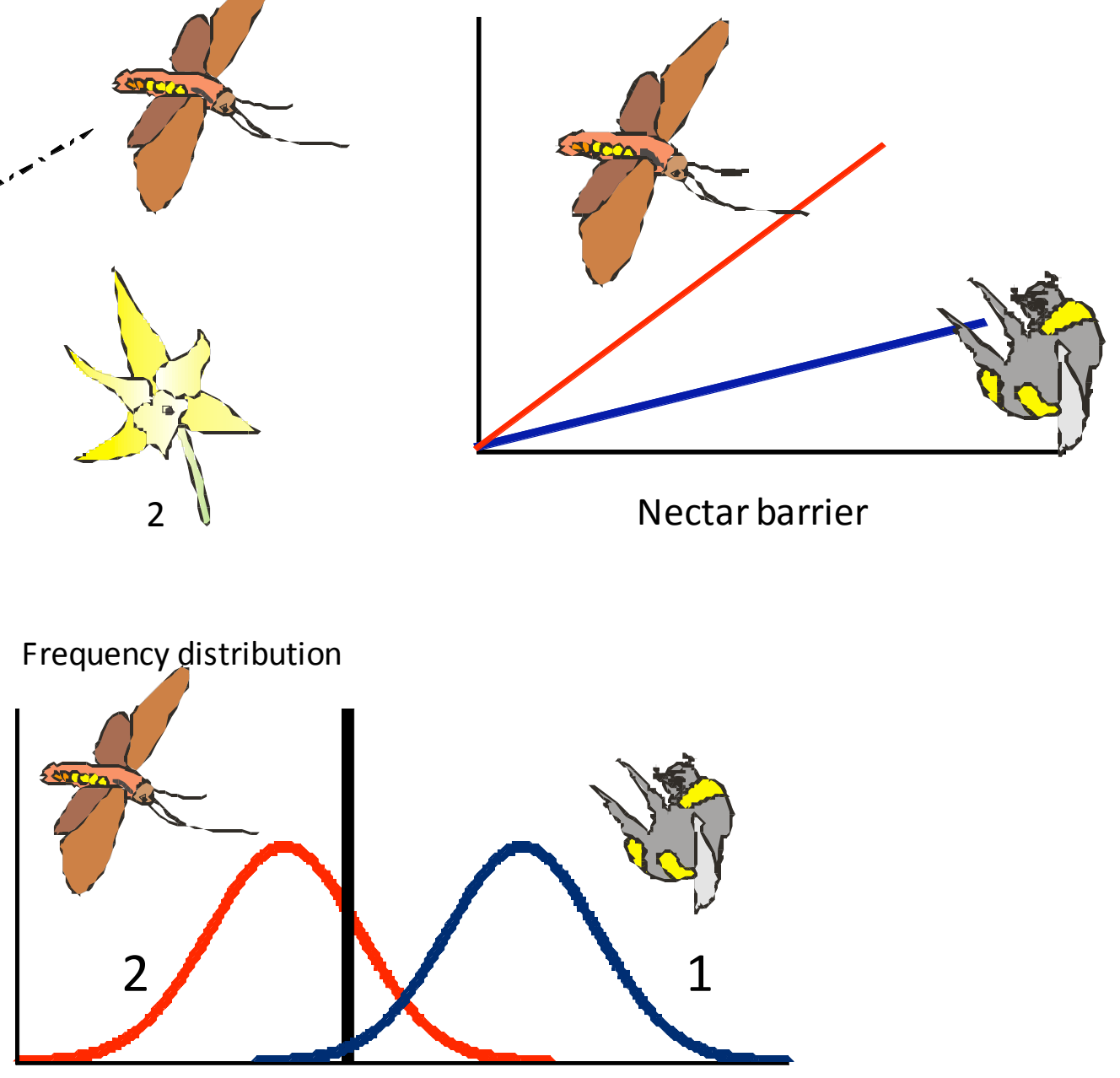

Nectar barrier

Fig. (1). Consider a community with two pollinator species (species A and B) and two plant species (species 1 and 2), and such that pollinator A is a more effective pollinator than B of plant species 1 (top left). Assume that flowers present nectar barriers. The higher the strength of a flower's barrier, the longer pollinators need to extract the nectar from the flower, but the effect of nectar barriers is stronger for pollinators of species B than A (top right). If pollinators are optimal foragers and there is variability in the strength of nectar barriers, A pollinators will preferentially exploit flowers with high barriers, and B pollinators will exploit flowers with low barriers. In the extreme case of high resource competition, there will be complete resource partitioning: pollinators of species B will visit flowers with nectar barriers below some threshold (indicated by the vertical bar in the bottom panel) and pollinators of species A will visit flowers with nectar barriers higher than the threshold. Plants of species 1 with high barriers (to the right of the vertical bar) in their flowers have two advantages over plants of the same species with low barriers: they are visited preferentially by the most effective pollinator (A), and they exchange pollen mainly with flowers of their own species. The strength of the nectar barrier therefore increases in flowers of plant species 1 .

Analytical models have focused on female fitness. To be able to include the male and female fitness components in the calculations of reproductive success, Rodríguez-Gironés and Santamaría (2007) developed a spatially explicit individual-based model. What the model does is to follow the movements of all pollinators in a virtual community as they search for nectar using simple foraging rules that allow them to obtain intake rates close to the ones they would obtain following the more complex optimal strategy. While foraging, pollinators move pollen grains from flower to flower, and the fate of each pollen grain in the community can be tracked. At the end of a blooming season, the program calculates the number of seeds produced and sired by each flower. Seeds disperse to a limited number of germination sites, and at each germination site a single seed is chosen at random to produce the plant that will be growing at the site the following season. The individual-based model shows the importance of incorporating foraging behaviour when modelling the evolution of floral traits. In the model there are two species of pollinators, one species with long proboscis and the other with short proboscis, and two plant species. At the beginning of the simulations, the distribution of corolla 
depths is the same for the flowers of the two plant species. Long-tongued pollinators specialise on flowers with relatively long corolla tubes, and short-tongued pollinators specialise on flowers with relatively short corolla tubes regardless of the plant species on which the flowers appear. Even when the probability of pollen transfer (from anthers to pollinators and from pollinators to stigmas) is the same for all plant-pollinator combinations, the foraging behaviour of pollinators introduces assortative mating: shallow flowers receive mostly pollen from shallow flowers, and flowers with deep corolla tubes receive mainly pollen from other flowers with deep corolla tubes. Assortative mating in turn implies that, when seed production is limited by the availability of pollen, there is disruptive selection on corolla tube length. After a few generations the distributions of corolla tube depth diverge and, by the end of the simulations, there is hardly any overlap between the distributions of corolla depth of the two plant species (Rodríguez-Gironés and Santamaría 2007). Notice that differences in pollination effectiveness are due entirely to differences in foraging behaviour of the pollinators: including asymmetries in the probability of pollen transfer between flowers and pollinators does not change the results.

In these models, resource partitioning proved to be a very powerful driver of floral diversification. The evolution of long corolla tubes did not require the consistent selection that has often been assumed (Ollerton 1996): long and short corolla tubes evolved despite the introduction of substantial amounts of noise. Perceptual noise, inducing pollinators to make suboptimal foraging choices (i.e., reducing the strength of resource partitioning); the introduction of large numbers of individuals (of a separate species) of pollen-collecting bees, which landed at every flower they encounter regardless of its corolla depth; and year-to-year fluctuations in population densities, had little effect on the results of the simulations (Rodríguez-Gironés and Santamaría 2007). In addition, the same principle can be applied to explain the coevolution of flowers with deep corolla tubes and pollinators with long proboscides (Rodríguez-Gironés and Llandres 2008).

Any trait that interferes with nectar exploitation can be considered a nectar barrier. The logic behind the model for the evolution of nectar concealment can be used to explain the evolution of many other floral traits, such as the association between red colouration and bird pollination (Rodríguez-Gironés and Santamaría 2004). To explain such association, Raven (1972) noted that 'red is the only colour of the spectrum that is at once inconspicuous to most insects and also an excellent "signal" of a high caloric reward for birds'. Raven's interpretation of inconspicuousness was soon transformed in much of the literature into invisibility, prompting Waser et al. (1996) to protest that "red flowers certainly are not "invisible to insects" as a pervasive truism of pollination biology claims" and Chittka and Waser (1997) to question the logic of Raven's (1972) hypothesis. But Raven (1972) never claimed that red flowers are invisible to insects. All he said is that they were inconspicuous to many insects. Indeed, bumblebees (Bombus terrestris) searching for large flowers against a green background take longer to detect flowers that make poor colour contrast with their backdrop, such as red flowers, than flowers of other colours, such as yellow or blue (Spaethe et al. 2001). Because birds can detect red flowers as well as yellow or blue flowers, this difference in search time is all we need to predict resource partitioning when bees and birds compete for nectar in a community with red flowers and flowers of other colours (Possingham 1992), and therefore red colour can evolve as a nectar barrier (Rodríguez-Gironés and Santamaría 2004, 2005) even if it does not prevent bees from exploiting red flowers.

As this example shows, floral displays are, in a certain sense, the mirror of nectar barriers. If nectar barriers promote resource partitioning because they make life more difficult for some pollinators than for others, floral displays will promote resource partitioning when they make life easier to some pollinators than to others. Just as red flowers are a better signal of nectar presence for birds than for bees (Spaethe et al. 2001), certain volatiles could promote resource partitioning (and hence be selected) if they are more easily detected by some pollinator species than others.

The models we have discussed rely on the observation that exploitative competition affects the foraging choices of pollinators. While exploitative competition is the most prevalent in the Mediterranean ecosystems that we know best, interference competition, which is common in bird-pollinated systems (E. J. Temeles, personal communication) and leads to resource partitioning (Pimm et al. 1985), could also affect the evolution of floral traits.

\section{ASSEMBLY RULES IN POLLINATION NETWORKS}

Assembly rules were first developed to explain observed patterns of composition in insular avian assemblages on the base of species competition driven by niche overlap (Diamond 1975). Their main tenant is that there are sets of constraints (rules) on community formation and maintenance from available species pools (e.g. Weiner \& Keddy 2001). They sparked nearly two decades of controversy that included the counter-proposal of the unified neutral theory of biodiversity, which states that the abundance and diversity of species in a community is determined mainly by random dispersal, speciation, and extinction (Hubbell 1997). Such controversy was recently extended to the analysis of plantpollinator assemblages and, while a suite of authors focused on identifying the assembly rules responsible for the structure and topology of plant-pollinator networks (such as the "forbidden rules " of Jordano et al. 2006, which parallel the "forbidden species combinations" of Diamond 1975), others argued that the latter solely arises as a direct consequence of the differences in abundance among randomlyinteracting plant and pollinator species (e.g. Vazquez 2005).

The structure of pollination networks is basically determined by three factors: the diversity and abundance of flowering plants in the community, the diversity and abundance of flower visitors, and the foraging choices of flower visitors. Although some pollinators visit flowers searching for resources other than food (such as breeding chambers, resins or fragrances, Ishida et al. 2009), these plantpollinator interactions are readily incorporated into our scheme if we extend foraging behaviour to include all resource-seeking strategies. While the factors that determine the abundance and diversity of flowering plants and pollinators are beyond the scope of this paper, once we know which plants and pollinators constitute the community there are a 
number of points we can make regarding the choices of flowers by pollinators.

As we have seen, optimal foraging theory predicts that differences in the structure and reward of co-occurring flowers should lead to a fair amount of resource partitioning (Possingham 1992; Peleg and Shmida 1992; RodríguezGironés 2006; Rodríguez-Gironés and Santamaría 2006). Resource partitioning should be stronger when flowers are spatially segregated in discrete patches (large trees can be considered patches) than when flowers grow intermingled, but even in this case there should be substantial preferences if competition for resources is strong (Rodríguez-Gironés and Santamaría 2006). The predictions from optimal foraging theory are indeed supported by a large number of field studies showing that the efficiency with which pollinators can exploit available flowers and resource competition both play an important role in the flowers chosen by individual pollinators (Heinrich 1976, Inouye 1978, 1980, Pyke 1982, Harder 1985, Laverty and Plowright 1985, Haber and Frankie 1989, Graham and Jones 1996, Irwin 2000, Temeles et al. 2002, Borrell 2005, Stang et al. 2006, and Campbell 2008).

If optimal foraging theory suggests that partial specialisation should infuse most pollination networks, most field studies of resource partitioning concentrate on small subsets of species. Recent studies of entire pollination networks, however, provide a convenient starting point to study how pollination networks are assembled. The topological properties of pollination networks change with their size following clear-cut patterns. The number of interactions increases and network connectivity (i.e. the ratio between realised and potential links) decreases as powers of network size (Olesen and Jordano 2002). Furthermore, most plant-pollinator networks are highly nested (i.e. specialists tend to interact with subsets of the species interacting with generalists) and network nestedness increases as the logarithm of size (Bascompte et al. 2003). Santamaría and Rodríguez-Gironés (2007) used these relationships to investigate how pollination networks might be assembled. They first calculated the relationship between network size and topological properties that one would expect to find for different assembly rules. In this context, an assembly rule is any mapping from phenotype space to the set $\{0,1\}$ : it is an algorithm that compares the phenotype of a flower and a pollinator and, on the basis of the comparison, produces a 1 if the pollinator is to visit the flower and a 0 otherwise. Santamaría and RodríguezGironés (2007) considered assembly rules based on the existence of exploitation barriers or complementarity traits. Exploitation barriers are rules of the form "pollinator A can only visit plant $\mathrm{X}$ if a certain trait of the pollinator is greater (or lower) than a threshold value determined by the phenotype of the flower". Tubular corollas, for example, are exploitation barriers because only pollinators with tongues long enough to access the nectar can consume it. - In this particular example, pollinators with strong mandibles can also pierce the corolla tubes to reach the nectar. The decision whether or not to exploit the flowers should be based on a Boolean OR comparison between two threshold rules: tongue sufficiently long OR mandibles sufficiently strong. Santamaría and Rodríguez-Gironés (2007), however, did not consider assembly rules with OR comparisons. Complementarity traits are of the form "pollinator A can only visit plant
$\mathrm{X}$ if a certain trait of the pollinator is sufficiently similar to a mean value determined by the phenotype of the flower". For instance, pollinators will only visit flowers if their peak of activity is sufficiently close to the flowers blooming peak that their phenologies overlap.

Comparison of the relationships between network size and topology expected from putative assembly rules with those observed in real networks allows the rejection of those assembly rules providing a poor fit to the data. The results from such comparisons can be summarised as follows. (1) Assembly rules based on a single trait performed poorly. This implies that, in real networks, the decision of a pollinator whether to visit a certain flower type or not must be based on several floral traits. (2) Assembly rules based solely on complementarity traits performed worse than assembly rules based solely on exploitation barriers. This implies that nectar concealment plays an important role in structuring pollination networks. (3) The best fit, however, was obtained combining complementarity traits and exploitation barriers. This was only to be expected, for we know that certain complementarity traits (such as phenology) necessarily play a role in the structure of pollination networks (Santamaría and Rodríguez-Gironés 2007).

A word on "neutral" models is also in order. Assuming that there is a lognormal distribution of species abundance in pollinator and plant species, and that the probability that a pollinator species visits a plant species is proportional to the abundance of the plant and the pollinator species (i.e. random interactions unrelated to phenotype) leads to expected relationships between network topology and size very similar to the relationship found in real pollination networks (Vázquez and Aizen 2003, 2004; Vázquez 2005; Santamaría and Rodríguez-Gironés 2007). Does this mean that we should abandon the quest for assembly rules? We do not think so. Parsimony implies that, when two models are equally good, the simplest one should be preferred. But the goodness of a model does not depend solely on the fit between predictions and observations: it depends just as much on the fit between assumptions and observations. Because pollinators show preferences for certain flowers (e.g. Stang et al. 2006), the basic assumption of the neutral model is violated and the neutral model can be rejected, no matter how well it fits the data in other respects. Besides, the simplicity of the neutral model is deceptive. Random interactions are not sufficient to account for the relationship between network size and topology (Santamaría and RodríguezGironés 2007). To account for this relationship, one needs to assume random interactions combined with lognormal frequency distributions of species abundance. If there is a correlation between abundance and phenotype (e.g. the fact that abundant species tend to be smaller - Damuth 1987), neutral models are not phenotype free. And the combination of random interactions with lognormal frequency distribution confounds causes and effects at the ecological and evolutionary levels. Are locally abundant species more generalist than rare species because of their abundance, or are generalist species more abundant than specialist species simply because they have more resources on which to feed at that specific location (i.e. in the spatial context in which the pollination network was measured)? Resolving this question requires precise knowledge on the regional and local abundances of pollinator species, and the spatial context in 
which foraging decisions are taken. All in all, neutral models of pollination networks open more and more complex questions than those they claim to resolve.

\section{FLORAL EVOLUTION IN POLLINATION NET- WORKS}

We have seen that floral traits that promote resource partitioning among co-occurring pollinators evolve easily in communities with two plant and two pollinator species. Although such traits evolve because they increase the flower fidelity of pollinators and therefore the proportion of pollen grains moving between conspecific flowers, the evolution of nectar barriers does not require total specialisation. On the contrary, nectar barriers evolve in the presence of substantial amounts of noise (Rodríguez-Gironés and Santamaría 2007).

A clear example of floral diversification through the evolution of nectar barriers that promote resource partitioning is provided by the system composed of purple-throated carib hummingbirds, Eulampis jugularis, and the flowers of Heliconia caribaea and H. bihai, of which they are the sole pollinators (Temeles et al. 2000). E. jugularis males are heavier and larger than females, but have shorter and straighter bills (Temeles et al. 2000). The difference in bill shape between males and females constitutes an adaptation to the differences in flower shape between $H$. caribaea (short, straight) and H. bihai (long, curved) on which males and females, respectively, feed (Temeles et al. 2000). While it might be tempting to conclude that the divergence in floral shape between $H$. caribaea and $H$. bihai has been triggered by differences in bill shapes between males and females in a coevolutionary process (similar to the one modelled by Rodríguez-Gironés and Llandres 2008 for corolla length), we are unaware of any data that might support this conclusion. Instead, in this system nectar barriers have led to the evolution of within-species polymorphisms, which appear in a single species (but not always the same one) within each island. In St. Lucia (West Indies), H. bihai has two flower morphs: where $H$. caribae is rare, the typical green morph (with long, curved flowers) is accompanied by a red-green morph with shorter and straighter flowers, defended by males against visits by females (Temeles et al. 2000). At the island of Dominica, in contrast, $H$. caribaea is the dimorphic species. At sites where the two morphs differ in flower length and curvature, males prefer shorter, straight flowers and females feed at longer, curved flowers (Temeles and Kress 2003). In each island, the floral polymorphism has been driven by assortative mating resulting from the feeding preferences of male and females.

In complex communities characterised by the simultaneous flowering of many plant species, all but the most abundant species will benefit from reducing pollen loss through an increase in the flower fidelity of pollinators (Feinsinger 1983). If the foraging behaviour of pollinators is at least as important a determinant of their pollination effectiveness as the mechanical fit between plant and pollinator, plants will be selected to develop floral traits that promote resource partitioning in any community. Nectar barriers are such traits: differences in pollinator size, morphology and physiology will translate into differences in their ability to surmount nectar barriers, and many nectar barriers will pro- mote resource partitioning among pollinators in essentially any community.

Consider, for example, variability in corolla depth. A flower with tubular corolla may be visited by hummingbirds in one community, hawkmoths in a second community and long-tongued bumblebees in a third community where hummingbirds and hawkmoths are absent. But in each community, the visitors of this flower are likely to specialise (at least partly) on the few plant species with tubular flowers (Pelag and Shmida 1992; Rodríguez-Gironés and Santamaría 2006). Even if a flowering plant finds itself surrounded by different plant and pollinator species across its geographical range, even if the pollinators in any one community differ from year to year, it may be selected to evolve long tubular corollas because this makes it different from other plant species, but different in a way that is relevant for pollinators - in a way that strengthens floral preferences (for or against the flower) and promotes resource partitioning and thereby transfer of conspecific pollen.

If many floral traits can promote resource partitioning among pollinators, some traits are more effective than others. Traits that prevent certain pollinators from exploiting the resources hidden in a flower will always lead to resource partitioning, while traits that change the profitability of a flower will only lead to resource partitioning when there is strong competition for resources. Thus, corolla depth is very effective because pollinators will quickly learn to avoid flowers if their tongues are too short to reach the nectar. Likewise, personate flowers, such as those of snapdragons, Antirrhinum, avoid all pollinators too small to push the palate and force their way through the throat of the corolla. Red colouration, on the other hand, is less effective. Bees will visit red flowers for nectar unless competition with hummingbirds is strong (Pleasants and Waser 1985), and they will continue visiting red flowers to collect pollen, because they experience no competition for this resource. The same happens with fragrances: some volatiles may be more easily detected, or more attractive, to certain pollinator groups than to others. But once a pollinator has found a flower, the profitability of the flower is independent of its fragrance. Therefore, under competition for resources a pollinator that cannot use smell to detect the flowers of a plant species should not specialise on searching for those flowers (as it will be at a disadvantage with respect to pollinators that can detect the flowers through its smell), but this pollinator should not avoid the flowers when encountered by chance.

If the foraging behaviour of pollinators plays an important role in determining their pollination effectiveness, it should result in strong selective pressures on plants to produce diverging flowers, flowers that are different from those of other plant species. But what can we say about the existence and meaning of pollination syndromes? Should we expect the evolution of correlations among particular floral traits?

Consider two dimensions, $\mathrm{D}_{1}$ and $\mathrm{D}_{2}$, along which resource partitioning can take place (such as corolla length and flower colour). If the pollinators that achieve high foraging efficiency at flowers with large values of $D_{1}$ are, by and large, the same ones that achieve high foraging efficiency when $\mathrm{D}_{2}$ is large (and vice versa), we should 
expect to find a positive correlation between the values of $\mathrm{D}_{1}$ and $\mathrm{D}_{2}$ of flowers between plants. In this scenario, flowers with large values of $D_{1}$ and low values of $D_{2}$ would partly attract and partly repel all pollinators, so the combination of large $\mathrm{D}_{1}$ and low $\mathrm{D}_{2}$ would not be very efficient at promoting resource partitioning. The evolution of bird pollination from bee pollination in monkeyflowers, Mimulus, offers an example of several nectar barriers that favour bird pollination over bee pollination (Bradshaw et al. 1995). In a similar manner, if the pollinators that benefit from large values of $D_{1}$ tend to benefit from low values of $\mathrm{D}_{2}$ (and vice versa), we expect a negative correlation between $D_{1}$ and $D_{2}$. However, if the ability of pollinators to forage efficiently at flowers with large values of $D_{1}$ does not predict the value of $D_{2}$ at which such pollinators will forage efficiently, there is no reason to expect a correlation between the levels of $D_{1}$ and $D_{2}$ of flowers belonging to different plants. It should be noted, however, that the previous discussion ignores the possibility that genetic correlations or other factors unrelated to pollination favour or prevent correlated evolution of floral traits (see e.g. Sargent et al. 2007 for a trade-off between the size and number of flowers).

Inasmuch as pollinator species belonging to the same taxonomic group share floral preferences, there is reason to expect the evolution of correlated floral traits, as predicted by the pollination syndromes. But we must be cautious. According to our interpretation, plants do not increase their reproductive success when their flowers are visited by few pollinator species. Rather, they increase their reproductive success when the pollinators that visit them visit few other flowering plant species. Floral divergence is selected for when it enhances temporal flower fidelity of individual pollinators. As long as this goal is achieved, plants obtain no extra benefit when all their visitors belong to the same taxonomical group. There is therefore no reason to expect that all flowers can be neatly pigeon-holed in one pollination syndrome.

It should be noted that, while our models study the tendency of flowers of co-occurring plant species to diverge, Jones (2001) proposes a similar scenario for within-species divergence when there is disruptive selection. In this context, it is suggested that floral traits unrelated to pollinator foraging performance will be more efficient drivers of floral divergence (Jones 2001). We are not aware of any quantitative comparison of the importance of nectar barriers and floral traits unrelated to the foraging efficiency of pollinators for floral divergence. Should the latter prove to be more important, there would be little reason to expect convergent evolution of floral traits.

What we certainly do not expect is that the aspect of a flower can be used to predict with any certainty the taxonomic group of the flower's pollinators. Instead, we expect the visitors of a flower to change with the community in which the flower is blooming. The foraging choices of pollinators depend on the flowers available, and on the number of competitors foraging at each of the flowers present. As competition studies have shown, a flower that is not profitable for a pollinator when a competitor is present may be included in its diet when the competitor is removed (Inouye 1978; Brown et al. 1981; Pyke 1982; Harder 1985; Pimm et al. 1985; Pleasants and Waser 1985), in agreement with the observation that many plant-pollinator interactions are labile and show great spatiotemporal heterogeneity.

We conclude our argument by clarifying that we do not believe that the foraging behaviour of pollinators is the single most important factor shaping plant-pollinator interactions. To achieve out-crossing, plants must ensure that pollen is transferred from anthers to pollinator and from pollinator to stigma, a process that requires adequate mechanical and behavioural fit between flowers and pollinators. In many cases, flowers that are visited by the same set of pollinators minimise stigma clogging and pollen loss by placing their pollen in specific parts of the pollinator's body. For instance, two South African species with similarly shaped flowers, Lapeirousia silenoides (Iridaceae) and Pelargonium sericifolium (Geraniaceae), respectively deposit their pollen on the dorsal and ventral side of the long-tongued flies that pollinate them; Goldblatt et al. 1995. If we have (over) stressed the importance of pollinator behaviour it is because we believe that this component is essential to understanding the evolution of floral divergence and it has not been sufficiently studied to date. We hope that our (deliberately biased) review will prompt ecologists to consider the effects of pollinator behaviour in their studies on plant reproductive success and floral evolution.

\section{TESTING THE THEORY}

We have argued that the foraging behaviour of pollinators must be taken into account to understand the evolution of floral traits, and we have used the results of evolutionary models to support our argument. The models clearly show that, if pollinators are optimal foragers, variability in floral traits can lead to resource partitioning among pollinators. Resource partitioning can be achieved if pollinators show (temporal) floral fidelity, and floral fidelity increases the probability that pollen from a certain flower ends up in a flower of a conspecific plant. According to our models, the foraging strategies of pollinators have the potential to affect the evolution of floral traits. The question that remains, however, is: how often has this potential been achieved?

A basic prediction of our foraging models, used as assumption in the evolutionary models, is that variability in floral traits leads to resource partitioning when there is competition for resources. We have already discussed a number of papers dealing with this issue, but the clearest demonstration of the effect of resource competition on resource partitioning among pollinators is probably the study of Inouye (1978). In his study site, larkspur, Delphinium barbeyi, and monkshood, Aconitum columbianum, are visited almost exclusively by two bumble bee species: Bombus appositus workers, with long proboscis length, specialise on larkspur flowers, and Bombus flavifrons workers, with intermediate proboscis length, specialise on monkshood flowers. When each bumble bee species was temporarily removed from the study site, however, the remaining species increased visitation to the flowers of the other, previously less utilised, plant species (Inouye 1978). Similar experiments could be performed with different systems to study the effect of other potential nectar barriers (such as flower colour) on resource use by competing pollinator species. It might be advisable to use artificial flowers for these experi- 
ments, as real flowers normally differ in more than one trait - although not all pollinator species visit artificial flowers in the field. Alternatively, one may take advantage of situations in which flowers differ in single traits of known genetic regulation, using approaches comparable to those used for the Mimulus system by Vickery (1995), Bradshaw \& Schemske (2003) or Ramsey et al. (2003). The foraging models can also be tested in finer detail, because they predict how resource partitioning should change as the proportions of flowers and pollinators with different morphs are modified.

A second prediction of the models is that resource partitioning among pollinators should increase the reproductive success of plants. It might be possible to test this prediction by growing a focal plant intermingled with plants of a second, background species. By changing the similarity between the flowers of the focal and background species, it should be possible to affect the degree of flower fidelity expressed by the pollinators and estimate its effect on the reproductive success (male and female components) of the focal plants.

A third prediction of the models is that the increase in assortative mating resulting from resource partitioning may lead to floral divergence. Addressing this prediction would require experimental data and an extrapolation to (or evaluation under) field conditions. A direct demonstration that pollinator foraging strategies can lead to floral divergence could be obtained, for example, by intermingling two crosssterile plant species with similar flowers. If there is assortative mating and traits are heritable, between-species differences in floral traits should be greater in the offspring than in the maternal generation (because individuals with flowers that differ more from those of the other species will lose less pollen to them). Note, however, that the flowers of the two plant species should appear similar (then progressively more different) to the pollinators, not to human observers.

An alternative procedure that may provide a more realistic test under field conditions may involve the use of polymorphic F2-hybrid populations to measure pollinator preferences and their phenotypic and genetic consequences in the F3 - as exemplified, for the Nicotiana complex, by the work of A. Ippolito and T. Holtsford (http://www.biosci. missouri.edu/holtsford/nicotiana/index.html). While not specifically concentrating in single traits, the use of polymorphic F2-hybrid populations in their natural setting (therefore allowing for the operation of natural ecological processes) has the advantage of releasing phenotypic variation and evaluating whether the operation of assortative mating suffices to segregate and re-associate traits putatively affected by pollinator-mediated selection during the speciation processes.

\section{ACKNOWLEDGEMENTS}

We thank Jordi Moya-Laraño, Ethan Temeles and Nickolas Waser for comments on a previous version of this manuscript. This work was supported by Ministerio de Ciencia e Innovación / FEDER (project CGL200763223/BOS) and Junta de Andalucía / FEDER (project RNM-340).

\section{REFERENCES}

Aristotle (ca. 350 B.C.) Historia animalium, republished in 1910 in D'Arcy Wentworth Thompson, translator. The works of Aristotle translated into English. Volume IV. Oxford University Press, London, UK.

Baker, HG (1963) Evolutionary mechanisms in pollination biology. Science, $139,877-83$.

Bascompte, J, Jordano, P, Melián, CJ \& Olesen, JM (2003) The nested assembly of plant-animal mutualistic networks. Proceeding National Academy Science USA, 100, 9383-87.

Belt, T (1874) The naturalist in Nicaragua (reprinted 1985). University of Chicago Press, Chicago and London.

Bernhardt, P (2000) Convergent evolution and adaptive radiation of beetlepollinated angiosperms. Plant System Evolution, 222, 293-320.

Borrell, BJ (2005) Long tongues and loose niches: evolution of euglossine bees and their nectar flowers. Biotropica, 37, 664-69.

Brown, JH, Kodric-Brown, A, Whitham, TD \& Bond, HW (1981) Competition between hummingbirds and insects for the nectar of two species of shrubs. South-western Naturalist, 26, 133-45.

Bradshaw Jr, HD, Wilbert, SM, Otto, KG \& Schemske, DW (1995) Genetic mapping of floral traits associated with reproductive isolation in monkeyflowers (Mimulus). Nature, 376, 762-65.

Bradshaw Jr, HD, Schemske, DW (2003) Allele substitution at a flower colour locus produces a pollinator shift in monkeyflowers. Nature, 426, 176-78.

Campbell, DR (2008) Pollinator shifts and the origin and loss of plant species. Annals of the Missouri Botanical Gardens, 95, 264-74.

Castellanos, MC, Wilson, P \& Thomson, JD (2004) 'Anti-bee' and 'probird' changes during the evolution of hummingbird pollination in Penstemon flowers. Journal of Evolutionary Biology, 17, 876-85.

Chittka, L \& Waser, N (1997) Why red flowers are not invisible to bees. The Israel Journal of Plant Sciences, 45, 169-83.

Condit, IJ \& Swingle, WT (1947) The fig. Chronica Botanica, Waltham, Massachuetts, USA.

Damuth, J (1987) Interspecific allometry of population density in mammals and other animals - the independence of body mass and population energy use. Biological Journal of the Linnean Society, 31, 193-246.

Darwin, C (1859) On the origin of species by means of natural selection, or the preservation of favoured races in the struggle for life. Murray, London.

Darwin, C (1862) On the Various Contrivances by Which British and Foreign Orchids Are Fertilized. Murray, London.

Delpino, F (1873) Ulteriori osservazioni e considerazioni sulla dicogamia nel regno vegetale. Atti Della Società Italiana di Scienze Naturali, $16,151-349$.

Delpino, F (1874) Ulteriori osservazioni e considerazioni sulla dicogamia nel regno vegetale. Atti Della Società Italiana di Scienze Naturali, $17,266-407$.

Diamond, JM (1975) Assembly of Species Communities. In: Cody, M \& Diamond, JM (Eds) Ecology and Evolution of Communities, Harvard University Press 342-444.

Fægri, K \& van der Pijl, L (1966) The Principles of Pollination Ecology. Pergamon, Oxford.

Fægri, K \& van der Pijl, L (1979) The Principles of Pollination Ecology. $3^{\text {rd }}$ edition. Pergamon, Oxford.

Feinsinger, P (1983) Coevolution and pollination. In: Futuyma, DJ \& Slatkin, M (Eds) Coevolution. Sinauer, Sunderland, MA 282-310.

Fenster, CB, Armbruster, WS, Wilson, P, Dudash, MR \& Thomson, JD (2004) Pollination syndromes and floral specialization. Annual Review of Ecology and Systematics, 35, 375-403.

Fretwell, SD \& Lucas, HL (1970) On territorial behaviour and other factors influencing habitat distribution inbirds. Acta Biotheoretica 19, 1636.

Glover, BJ, Bunnewell, S \& Martin, C (2004) Convergent evolution within the genus Solanum: the specialised anther cone develops through alternative pathways. Gene, 331, 1-7.

Goldblatt, P (1986) Convergent Evolution of the 'Homeria' flower type in six new species of Moraea (Iridaceae-Irideae) in Southern Africa. Annals of the Missouri Botanical Garden, 73, 102-16.

Goldblatt, P, Manning, JC \& Bernhardt, P (1995) Pollination biology of Lapeirousia subgenus Lapeirousia (Iridaceae) in Southern Africa: floral divergence and adaptation for long-tongued fly pollination. Annals of the Missouri Botanical Garden, 82, 517-34.

Graham, L \& KN Jones (1996) Resource partitioning and per-flower foraging efficiency in two bumble bee species. American Midland Naturalist, 136, 401-6. 
Grant, V \& Grant, KA (1965) Flower Pollination in the Phlox Family. Columbia Univ. Press, New York.

Haber, WA \& GW Frankie (1989) A tropical hawkmoth community: Costa Rican dry forest Sphingidae. Biotropica, 21, 155-72.

Harder, LD (1985) Morphology as a predictor of flower choice by bumblebees. Ecology, 66, 198-210.

Heinrich, B (1976) Resource partitioning among some eusocial insects: bumblebees. Ecology, 57, 874-89.

Heinrich, B \& Raven, PH (1972) Energetics and pollination ecology. Science, 176, 597-602.

Herodotus (485-25 BC) Historiae. Republished in Rawlinson, G, translator. Wordsworth classics of world literature. Ware, UK.

Herrera, CM (1996) Floral traits and plant adaptation to insect pollinators: a devil's advocate approach. In: Lloyd, DG \& Barrett, SCH (Eds) Floral Biology: Studies on Floral Evolution in Animal-Pollinated Plants, Chapman \& Hall, New York 65-87.

Herrera, CM (2002) What Darwin forgot to mention about orchids. Evolution, 56, 856-58.

Hingston, AB \& McQuillan, PB (2000) Are pollination syndromes useful predictors of floral visitors in Tasmania? Austral Ecology, 25, 6009.

Hubbell, SP (2001) The Unified Neutral Theory of Biodiversity and Biogeography. Princeton University Press, Princeton.

Inouye, DW (1978) Resource partitioning in bumble-bees: experimental studies of foraging behavior. Ecology, 59, 672-78.

Inouye, DW (1980) The effect of proboscis and corolla tube lengths on patterns and rates of flower visitation by bumblebees. Oecologia, $45,197-201$

Irwin, RE (2000) Hummingbird avoidance of nectar-robbed plants: spatial location or visual cues. Oikos, 91, 499-506.

Ishida, C, Kono, M \& Sakai, S (2009) A new pollination system: brood-site pollination by flower bugs in Macaranga (Euphorbiaceae). Annals of Botany, 103, 39-44.

Janzen, DH (1971) Euglossine bees as long-distance pollinators of tropical plants. Science, 171, 203-5.

Jones, KN (2001) Pollinator-mediated assortative mating: causes and consequences. In: Chittka, L \& Thomson, JD (Eds) Cognitive ecology of pollination. Animal behaviour and floral evolution, Cambridge University Press, Cambridge 259-73.

Jordano, P, Bascompte, J, \& Olesen, JM (2006) The ecological consequences of complex topology and nested structure in pollination webs. In: Waser NM \& Ollerton J (Eds) Plantpollinator interactions: From specialization to generalization. The University of Chicago Press, 173-99.

Kevan, PG \& Phillips, TP (2001) The economic impacts of pollinator declines: an approach to assessing the consequences. Conservation Ecology, 5: 8. [online]

Kölreuter JG (1761) Vorläufige Nachrichten von einigen das Geschlecht der Pflanzen betreffenden Versuchen und Beobachtungen. Gleditschischen Handlung, Leipzig.

Laverty, TM (1980) The flower-visiting behaviour of bumblebees: floral complexity and learning. Canadian Journal of Zoology, 58, 132435 .

Laverty, TM \& Plowright, RC (1985) Competition between hummingbirds and bumble bees for nectar in flowers of Impatiens biflora. Oecologia, 66, 25-32.

Meeuse, BJD (1981) The history of pollination. Ronald Press, New York.

Momose, K, Yumoto, T, Nagamitsu, T, Kato, M, Nagamasu, H, Sakai, S, Harrison, RD, Itioka, T, Hamid, AA \& Inoue, T (1998) Pollination biology in a lowland dipterocarp forest in Sarawak, Malaysia. I. Characteristics of the plant-pollinator community in a lowland dipterocarp forest. American Journal of Botany, 85, 1477-1501.

Müller, HLH (1873) Die Befruchtung der Blumen durch Insekten. Wilhelm Engelmann, Leipzig.

Olesen, JM \& Jordano, P (2002) Geographic patterns in plant-pollinator mutualistic networks. Ecology, 83, 2416-24.

Ollerton, J (1996) Reconciling ecological processes with phylogenetic patterns: the apparent paradox of plant-pollinator systems. Journal of Ecology, 84, 767-69.

Ollerton, J, Alarcon, R, Waser, NM, Price, MV, Watts, S, Cranmer, L, Hingstons, A, Peter, CI \& Rotenberry, J (2009) A global test of the pollination syndrome hypothesis. Annals of Botany, 103, 1471-80.

Peleg, B \& Shmida, A (1992) Short-run stable matchings between bees and flowers. Games and Economic Behavior, 4, 232-51.
Pérez, R, Vargas, P \& Arroyo, J (2004) Convergent evolution of flower polymorphism in Narcissus (Amaryllidaceae). New Phytologist, $161,235-52$

Pimm, SL, Rosenzweig, ML \& Mitchell, W (1985) Competition and food selection: field tests of a theory. Ecology, 66, 798-807.

Pleasants, JM \& Waser, NM (1985) Bumblebee foraging at a "hummingbird" flower: reward economics and floral choice. American Midland Naturalist, 114, 283-91.

Possingham, HP (1992) Habitat selection by two species of nectarivore: habitat quality isolines. Ecology, 73, 1903-12.

Pyke, GH (1982) Local geographic distribution of bumblebees near Crested Butte, Colorado: competition and community structure. Ecology, $63,555-73$.

Ramsey, J, Bradshaw, HD Jr. \& Schemske, DW (2003) Components of reproductive isolation between the monkeyflowers Mimulus lewisii and M. cardinalis (Phrymaceae). Evolution, 57, 1520-34

Raven, PH (1972) Why are bird-visited flowers predominantly red? Evolution, 26, 674

Reasoner, PW (1891) The condition of tropical and semi-tropical fruits. U.S. Department of Agriculture. Division of Pomology. Bulletin Number 1, Washington, D.C.

Robertson, C (1928) Flowers and insects. Lists of visitors of four hundred and fifty-three flowers. Charles Robertson, Carlinville, IL.

Rodríguez-Gironés, MA (2006) Resource partitioning among flower visitors: extensions of Possingham's model. Evolutionary Ecology Research, 8, 765-83.

Rodríguez-Gironés, MA \& Llandres, AL (2008) Resource Competition Triggers the Co-Evolution of Long Tongues and Deep Corolla Tubes. PLoS ONE, 3, e2992. doi:10.1371/journal.pone.0002992.

Rodríguez-Gironés, MA \& Santamaría, L (2004) Why are so many bird flowers red? PLoS Biol 2(10), e350. doi: 10.1371/journal. pbio.0020350

Rodríguez-Gironés, MA \& Santamaría, L (2005) Resource partitioning among flower visitors and evolution of nectar concealment in multi-species communities. Proceedings of the Royal Society B: Biological Sciences, 272, 187-92.

Rodríguez-Gironés, MA \& Santamaría, L (2006) Models of optimal foraging and resource partitioning: deep corollas for long tongues. Behavioral Ecology, 17, 905-10.

Rodríguez-Gironés, MA \& Santamaría, L (2007) Resource competition, character displacement, and the evolution of deep corolla tubes. American Naturalist, 170, 455-64.

Santamaría, L \& Rodríguez-Gironés, MA (2007) Linkage rules for plantpollinator networks: Trait complementarity or exploitation barriers? PLoS Biol 5(2), e31. doi:10.1371/journal.pbio.0050031.

Sargent, RD \& Otto, SP (2006) The role of local species abundance in the evolution of pollinator attraction in flowering plants. American Naturalist, 167, 67-80

Sargent, RD, Goodwillie, C, Kalisz, S \& Ree, RH (2007) Phylogenetic evidence for a flower size and number-trade-off. American Journal of Botany, 94, 2059-62.

Spaethe, J, Tautz, J, \& Chittka, L (2001) Visual constraints in foraging bumblebees: Flower size and color affect search time and flight behavior. Proceedings of the National Academy of Sciences USA, 98, 3898-3903.

Sprengel, CK (1793) Das entdeckte Geheimniss der Natur im Bau und in der Befruchtung der Blumen. Berlin, Vieweg.

Stang, M, Klinkhamer, PGL \& Van der Meijden, E (2006) Size constraints and flower abundance determine the number of interactions in a plant-flower visitor web. Oikos, 112, 111-21.

Stebbins, GL (1970) Adaptive radiation of reproductive characteristics in angiosperms. I: Pollination mechanisms. Annual Review of Ecology and Systematics, 1, 307-26.

Strauss, SY \& Whittall, JB (2006) Non-pollinator agents of selection on floral traits. In: Harder, LD \& Barrett, SCH (Eds) Ecology and evolution of flowers, Oxford University Press, Oxford.

Strickler, K \& Vinson, JW (2000) Simulation of the effect of pollinator movement on alfalfa seed set. Environmental Entomology, 29, 90718.

Temeles, EJ \& Kress, WJ (2003) Adaptation in a plant-hummingbird association. Science, 300, 630-33.

Temeles, EJ, Linhart, YB, Masonjones, M \& Masonjones, HD (2002) The role of flower width in hummingbird bill length-flower length relationships. Biotropica, 34, 68-80. 
Temeles, EJ, Pan, IL, Brennan, JL \& Horwitt, JN (2000) Evidence for ecologica causation of sexual dimorphism in a hummingbird. Science, 289, 441-443.

Vázquez, DP (2005) Degree distribution in plant-animal mutualistic networks: forbidden links or random interactions? Oikos, 108, 421426.

Vázquez, DP \& Aizen, MA (2003) Null model analyses of specialization in plant-pollinator interactions. Ecology, 84, 2493-2501.

Vázquez, DP \& Aizen, MA (2004) Asymmetric specialization: a pervasive feature of plant-pollinator interactions. Ecology, 85, 1251-1257.

Vickery, RK Jr. (1995) Speciation in Mimulus, or, can a simple flower color mutant lead to species divergence? Great Basin Naturalist, 55, 177-80.

Waser, NM (1983) The adaptive nature of floral traits: Ideas and evidence. In: Real, L. (Ed.) Pollination Biology. Academic Press, London.
Waser, NM, Chittka, L, Price, MV, Williams, NM \& Ollerton, J (1996) Generalization in pollination systems, and why it matters. Ecology, 77, 1043-1060.

Waser, NM \& Price, MV (1998) What plant ecologists can learn from zoology. Perspectives in Plant Ecology, Evolution and Systematics, 1, 137-50.

Waterman, RJ, Pauw, A, Barraclough, TG \& Savolainen, V (2009) Pollinators underestimated: A molecular phylogeny reveals widespread floral convergence in oil-secreting orchids (sub-tribe Coryciinae) of the Cape of South Africa. Molecular Phylogenetics and Evolution, 51, 100-10.

Weiher, E \& Keddy, P (2001) Ecological Assembly Rules: Perspectives, Advances, Retreats. Cambridge University Press.

Received: February 18, 2010

Revised: March 23, 2010

Accepted: March 27, 2010

(C) Rodríguez-Gironés and Santamaría; Licensee Bentham Open.

This is an open access article licensed under the terms of the Creative Commons Attribution Non-Commercial License (http://creativecommons.org/licenses/bync/3.0/), which permits unrestricted, non-commercial use, distribution \& reproduction in any medium, provided the work is properly cited. 